\title{
Impact of Endoplasmic Reticulum Stress Sensors on Pectolinarin Induced Apoptosis
}

\author{
Ji-Hye Song ${ }^{1}$, Kisang Kwon ${ }^{1}$, O-Yu Kwon ${ }^{1}$, Eun-Ryeong Lee ${ }^{2}$, Seung-Whan Kim ${ }^{3}$ and \\ Kyung-Hee Kang ${ }^{4 *}$ \\ ${ }^{1}$ Departments of Anatomy and Cell Biology, College of Medicine, Chungnam National University, Daejeon, South Korea, \\ 2 Department of Biomedical Laboratory Science, College of Health and Welfare, Kyungwoon University, Gumi, South Korea, \\ ${ }^{3}$ Department of Emergency Medicine, College of Medicine, Chungnam National University, Daejeon, South Korea, \\ ${ }^{4}$ Department of Dental Hygiene, College of Medical Science, Konyang University, Daejeon, South Korea
}

OPEN ACCESS

Edited by:

Deepak Gupta,

Maharaja Agrasen Institute of

Technology, India

Reviewed by:

Sandeep Kumar Satapathy,

VIT University, India

Gyoo-Soo Chae,

Baekseok Culture University,

South Korea

Shruti Mishra,

VIT-AP University, India

*Correspondence:

Kyung-Hee Kang

dhkhkang@konyang.ac.kr

Specialty section:

This article was submitted to

Digital Public Health,

a section of the journal

Frontiers in Public Health

Received: 11 June 2020

Accepted: 27 July 2020

Published: 09 September 2020

Citation:

Song J-H, Kwon K, Kwon O-Y, Lee E-R, Kim S-W and Kang K-H

(2020) Impact of Endoplasmic

Reticulum Stress Sensors on

Pectolinarin Induced Apoptosis.

Front. Public Health 8:478.

doi: 10.3389/fpubh.2020.00478
Pectolinarin, [5,7-Dihydroxy 4',6-dimethoxyflavone 7-rutinoside, 7-[[6-O-(6-Deoxy- $\alpha$-Lmannopyranosyl)- $\beta$-D-glucopyranosyl] oxy]-5-hydroxy-6-methoxy-2-(4-ethoxyphenyl)$4 \mathrm{H}$-1-benzopyran-4-one], has been stated one of the major compounds in Cirsium nipponicum (Maxim.) Makino. It is characterized by biological functions of hepatoprotective, anti-inflammatory and antiobesity activities. In this research, it was explained that pectolinarin causes apoptosis in PC12 cells conducted by DNA fragmentation and formation on apoptotic bodies through the activation of ER stress sensors (ATF6 fragmentation and elF2 $\alpha$ phosphorylation). The result of treating the PC12 cells with $50 \mu \mathrm{M}$ pectolinarin for $24 \mathrm{~h}$ has come to increase ATF6 mRNA expression up to 1.6 times, PERK expression up to 1.7 times and IRE1 expression up to 1.4 times, respectively, compared to those of the control. ATF6 fragmentation by pectolinarin treatment was increased about 2 times compared with its control, and phosphorylation of elF2 $\alpha$ was increased 2.5 times. The results proposed that the perception of the molecular mechanisms underlying pectolinarin-caused apoptosis may be useful in new natural medicinal products and health supplements for the apoptosis-related diseases.

Keywords: pectolinarin, PC12 cells, endoplasmic reticulum (ER), stress, sensor

\section{INTRODUCTION}

Cirsium nipponicum (Maxim). Makino is an asteraceae perennial herb, called Island thistle (in English) and Mul-eong-gcong-kwi (in Korean), distributed widely throughout Ul Leung Do (an island located at the east of Korean Peninsula), and it is used as a medicinal or edible plant (1). In Oriental medicine, roots are generally used for disease treatment, therefore the leaves and stems are collected when flowers are in full bloom (2). Traditionally, it has been widely used as a traditional medicinal product for the treatment of bleeding, hepatitis, hypertension and blood circulation diseases $(3,4)$. Recently, pharmacological studies have shown that its extract has antitumor (5) and antidiabetic (6), antioxidant (7), anti-inflammatory (8), and antifungal functions (9). This contains a significant amount of flavonoid mixtures, among which pectolinarin has been reported to be the major compound (10). The important biological activity of pectolinarin reported so far is as follows; anti-inflammatory, hepatoprotective, antiobesity activities and analgesic effect (11). However, the biological function of pectolinarin is not precisely defined. 
The endoplasmic reticulum (ER) is an organelle spotted in eukaryotic cells. It is a very important manufacturing site for the post-translational step that mediates the synthesis, folding, modification and transport of secretory proteins. Some kinds of stressors that disrupt the endoplasmic reticulum function lead to accumulation of un-, mis-, misfolded proteins in the endoplasmic reticulum lumen (12). The endoplasmic reticulum stress induces ER-stress adaptable signal called the unfolded protein response (UPR) to maintain endoplasmic reticulum homeostasis via activation of endoplasmic reticulum chaperones, such as binding immunoglobulin protein $(\mathrm{BiP})$, glucose-regulated protein 94 (GRP94), calnexin, calreticulin, endoplasmic reticulum protein 29 (ERp29), heat shock protein 47 (HSP47) and protein disulfide isomerase (PDI), which regulates three types of endoplasmic reticulum stress sensors, containing IRE1(Inositol Requiring Enzyme 1), PERK(PKR-like ER kinase) and initiating ATF6(transcription factor 6) (1315). Though this study did not fully document the specific significance of endoplasmic reticulum stress protein expression, it demonstrated that pectolinarin controls the expression of endoplasmic reticulum stress sensors associated with apoptosis using the PC12 cells, which is widely used as a classical neuronal cell model.

\section{MATERIALS AND METHODS}

\section{Sample, Cell Culture, and MTT Assay}

Pectolinarin (chemical formula, $\mathrm{C}_{29} \mathrm{H}_{34} \mathrm{O}_{15}$; molar mass, 622.57 $\mathrm{g} / \mathrm{mol}$ ) purified at a purity of $>95.0 \%$ (HPLC) derived from Cirsium nipponicum (Maxim.) Makino was gifted by National Development Institute of Korean Medicine (NIKOM). The PC12 cells were cultured in collagen-coated plates or flasks containing 85\% RPMI-1640 medium, augmented with $25 \mathrm{mM}$ HEPES buffer, horse serum $10 \%$ heat inactivated, fetal bovine serum $5 \%$ heat inactivated, $1 \mathrm{mM}$ sodium pyruvate, $1 \mathrm{~g} / \mathrm{l} \mathrm{d}$ (+) -glucose, $2 \mathrm{mM}$ L-glutamine, $25 \mu \mathrm{g} / \mathrm{ml}$ streptomycin and $25 \mathrm{U} / \mathrm{ml}$ penicillin (all Gibco; Thermo Fisher Scientific, Inc., USA). The cells were preserved in a humidified incubator at $37^{\circ} \mathrm{C}$ at $5 \% \mathrm{CO}_{2}$ and the medium was changed every $48 \mathrm{~h}$. The effects of pectolinarin on cell survival of the PC12 cells were made using an MTT kit (Sigma-Aldrich, USA). Color development was observed at $595 \mathrm{~nm}$ with a reference wavelength of $650 \mathrm{~nm}$ using the Sunrise ${ }^{\mathrm{TM}}$ microplate reader (Tecan Trading AG, Switzerland).

\section{RT-PCR Analysis}

Each gene expression was mainly determined by RT-PCR as described below. RT-PCR conditions included 30 cycles comprising each of the following: $94^{\circ} \mathrm{C}$ for $30 \mathrm{~s}, 58^{\circ} \mathrm{C}$ for $30 \mathrm{~s}$ and $72^{\circ} \mathrm{C}$ for $1 \mathrm{~min}$ (10 $\mathrm{min}$ in the final cycle) employing the primers with Taq DNA polymerase (Solgent Co., Ltd., Korea). The RT-PCR primers were provided by Bioneer Corporation, Korea. The RT-PCR primers were as follows: IRE1 forward, $5^{\prime}$ ACC ACC AGT CCA TCG CCA TT-3' and reverse, 5'-CCA CCC TGG ACG GAA GTT TG-3'; ATF6 forward, 5' -CTA GGC CTG GAG GCC AGG TT-3' and reverse, 5' -ACC CTG GAG
TAT GCG GGT TT-3'; PERK forward, 5'-GGT CTG GTT CCT TGG TTT CA-3' and reverse, 5'-TTC GCT GGC TGT GTA ACT TG-3'; BiP forward, 5'-AGT GGT GGC CAC TAA TGG AG-3' and reverse, 5'-TCT TTT GTC AGG GGT CGT TC-3'. Bcl-xl forward, 5'-CCC CAG AAG AAA CTG AAC CA-3' and reverse, $5^{\prime}$-GCA GAA CTA CAC CAG CCA CA-3'; Bax forward, 5'-AGG GGC CTT TTT GTT ACA GG-3' and reverse, 5'-GAT CAG CTC GGG CAC TTT AG-3' Bcl2 forward, 5'-AAG CTG CAC AGC GGG GCT A-3' and reverse, 5'-CAG ATG CCG GTT CAG GTA CT-3' Bak1 forward, 5' -TTA CCT CCA GCA GGA AC-3' and reverse, 5'-ACC ACC TCT CTG TGC AAT CC-3' LC3a forward, 5'-GCC TGT CCT GGA TAA GAC CA$3^{\prime}$ and reverse, 5'-GTT CAC CAG GAA GG-3' Beclin forward, 5'-GTG CTC CTG TGG AAT GGA AT-3' and reverse, 5'-GCT GCA CAC AGT CCA GAA AA-3' Cal forward, 5'-GGC ATC TTC ATC CCA GTC AT- $3^{\prime}$ and reverse, $5^{\prime}$-CTC CTC TCT GCT CCT CAT GG-3' PDI forward, 5'-CAG AGT TCT GCC ACC GCT TC- $3^{\prime}$ and reverse, $5^{\prime}$-TCC TCG AGA TCG TCA TC- $3^{\prime}$ ERp29 forward, 5'-CTC CTC TCT GCT CCT CAT GG-3' and reverse, 5'-GCT CCA TGT TCA GCT TGT CA-3' Xbp1 forward, 5'-AAA CAG AGT AGC TCA GAC TGC-3' and reverse, 5' TCC TCC TGG GTA GAC CTC TGG GAG-3'. All chemicals were acquired from Sigma-Aldrich; Merck KGaA. The figures show the outputs of a representative experiment in triplicate with different sampling units.

\section{Western Blotting}

Immunoblotting was carried out according to the standard procedure. The PC12 cells treated with pectolinarin were dissolute by the addition of SDS sample buffer [62.5 mM Tris$\mathrm{HCl}, \mathrm{pH}$ 6.8, 6\% (w/v) SDS, 30\% glycerol, 125 mM DTT, $0.03 \%$ $(\mathrm{w} / \mathrm{v})$ bromphenol blue] and parted by SDS-PAGE. The proteins were moved to a nitrocellulose membrane, and the membrane was developed with the main antibodies. The rabbit anti-eIF $2 \alpha$ antibody, eIF $2 \alpha-\mathrm{P}$ antibody and goat anti-actin antibody were acquired from Santa Cruz Biotechnology, Inc., USA. The mouse anti-ATF6 antibody was acquired from Novus Biologicals, LLC, USA. The horseradish peroxidase-conjugated anti-rabbit, antigoat and anti-mouse IgG secondary antibodies were acquired from Santa Cruz Biotechnology, Inc. Goat anti-actin antibody was used to systematize the quantity of sample proteins. The blots were developed by utilizing an upgraded chemiluminescence Western blotting detection system kit (Amersham, Sweden). The experiments were carried out in triplicate, and the protein bands were defined employing Image J software (version 1.48; https:// imagej.nih.gov/ij/).

\section{DNA Fragmentation Assay and Hoechst 33342 Staining}

Following the treatment with pectolinarin, the PC12 cells were dissolute in $100 \mu \mathrm{l} 10 \mathrm{mM}$ Tris- $\mathrm{HCl}$ buffer ( $\mathrm{pH}$ 7.4) having $10 \mathrm{mM}$ EDTA and $0.5 \%$ Triton X-100. After centrifugation for $5 \mathrm{~min}$ at $16,000 \mathrm{x} \mathrm{g}$, the supernatant dealt with RNase A and proteinase K (Promega Corporation, Madison, WI, USA). Eventually, $20 \mu \mathrm{l}$ of $5 \mathrm{M} \mathrm{NaCl}$ and $120 \mu \mathrm{l}$ isopropanol were put together and preserved with ice for $1 \mathrm{~h}$. Following centrifugation for $15 \mathrm{~min}$ at $16,000 \mathrm{x}$, the DNA pellets were dissolved in 
$20 \mu \mathrm{l}$ TE buffer. The DNA samples were stuffed onto a $0.7 \%$ agarose gel and noted using a UV source after ethidium bromide (Sigma-Aldrich; Merck KGaA) staining. After treatment with pectolinarin, the PC12 cells were developed in incubator for 30 min with Hoechst 33342 (Molecular Probes; Thermo Fisher Scientific, Inc.) loading dye and washed in ice-cold 1X PBS. After following staining for $10 \mathrm{~min}$, the stained cells were screened by employing a fluorescence microscope (Axio Scope A1; Zeiss $\mathrm{GmbH}$, Germany) at $340 \mathrm{~nm}$.

\section{RESULTS AND DISCUSSION}

Cell Viability and ER Chaperone Expression

Pectolinarin is a representative component of flavonoid mixtures isolated from Cirsium nipponicum (Maxim.) Makino (10). It has anti-inflammatory activities and is similar in chemical structure to linarin $(8,16,17)$. It is well-known that one of the remarkable features of cellular injury is leakage of soluble lactate dehydrogenase (LDH) from the cells stimulated by any stimulant. As a result of assaying, pectolinarin did not induce LDH leakage, so it was proven not to cause cellular injury within a certain concentration (18). In this study, the PC12 cell line used here is extracted from a pheochromocytoma cell of the rat adrenal medulla having a mixture of neuroblastic and eosinophilic cells. This cell line has been extensively used in in vitro studies to examine various neuronal diseases $(19,20)$. At the beginning of this study, we tested the effects of pectolinarin on cell viability in the MTT assay following at $1,5,10,50$, and $100 \mu \mathrm{g} / \mathrm{ml}$ of pectolinarin treatment for $24 \mathrm{~h}$. As shown in Figure 1A, the result of the MTT assay has shown that no morphological differences were shown at concentrations below $100 \mu \mathrm{g} / \mathrm{ml}$ pectolinarin treatment and control cells were observed.

The endoplasmic reticulum which has newly-synthesized secretory and cell membrane proteins are post-translationally modified and correctly folded. Protein modification and folding in the endoplasmic reticulum are impaired by the endoplasmic reticulum chaperones, such as BiP, GRP94, calnexin, calreticulin, ERp29 and PDI. One of the most abundant endoplasmic reticulum chaperones in the endoplasmic reticulum lumen is $\mathrm{BiP}$, a member of the Hsp70 family of proteins, which perceives newly synthesized proteins as they are transferred in the endoplasmic reticulum and sustains them in a state of competent for following folding and oligomerization. Like $\mathrm{BiP}$, each endoplasmic reticulum chaperone exerts a unique function in the endoplasmic reticulum lumen to complete the correct protein folding (1315). Although the effect of pectolinarin on cell viability was not confirmed in the MTT assay, the expression of endoplasmic reticulum chaperones (PDI, BiP, calnexin and ERp29) which indicate the degree of cell stress, was examined by pectolinarin treatment in the PC12 cells. As presented in Figure 1B, notable endoplasmic reticulum chaperone expression was not observed in the PC12 cells treated with pectolinarin. In summary, no remarkable cell viability and endoplasmic reticulum chaperone expression were observed by pectolinarin treatment on the PC 12 cells.

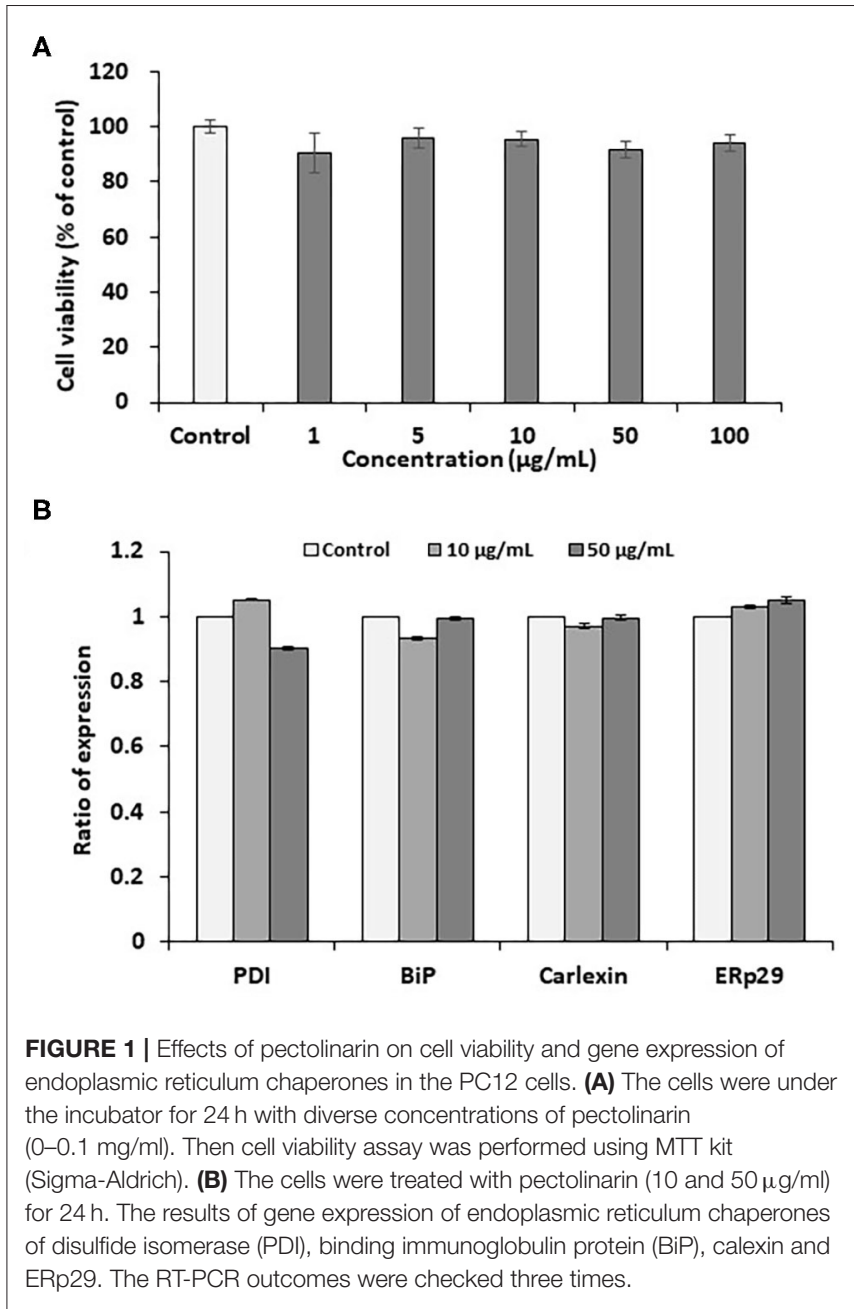

\section{Expression and Activation of Endoplasmic Reticulum Sensors}

Although pectolinarin induces unremarkable cell viability and endoplasmic reticulum chaperone expression, next we have examined the gene expression of endoplasmic reticulum stress sensors (ATF6, PERK and IRE1) and the activations by pectolinarin treatment on the PC 12 cells. Under altered endoplasmic reticulum homeostasis, the endoplasmic reticulum stress signal transduction pathway is mediated via being active of ER(endoplasmic reticulum)- stress sensors. IRE1 activates XBP mRNA cleaving, producing an activated form of the $\mathrm{XBP} 1$ protein. PERK induces phosphorylation of the eIF2 $\alpha$, which hinders translation initiation. Active ATF6 is cleaved at the cytosolic face and the resulting $\mathrm{N}$-terminal cytoplasmic domain ties to the endoplasmic reticulum stress-responding element, which enhances endoplasmic reticulum chaperone gene expression (21).

We have determined the expression of endoplasmic reticulum stress sensors under same experimental conditions as described in Figure 1B. As showed in Figure 2A, dealing the PC12 cells with $50 \mu \mathrm{M}$ pectolinarin for $24 \mathrm{~h}$ increased ATF6 mRNA 


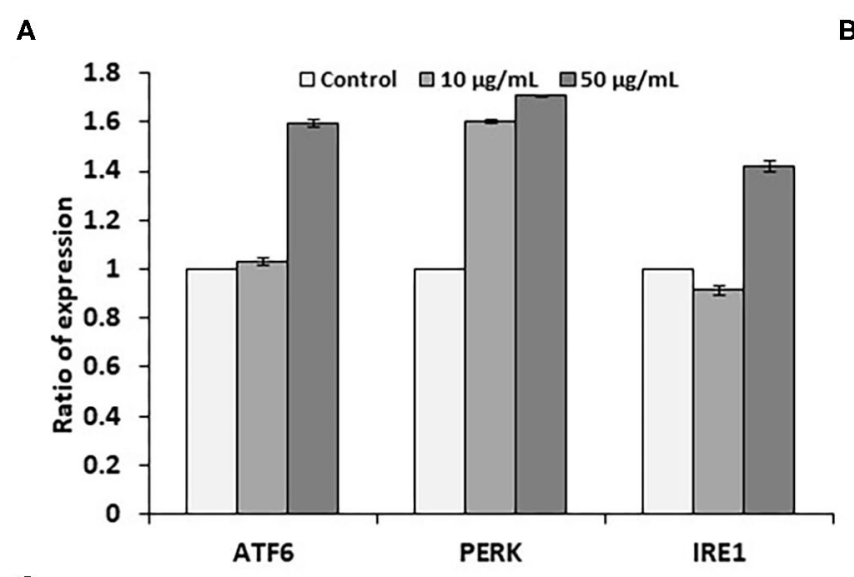

B

C

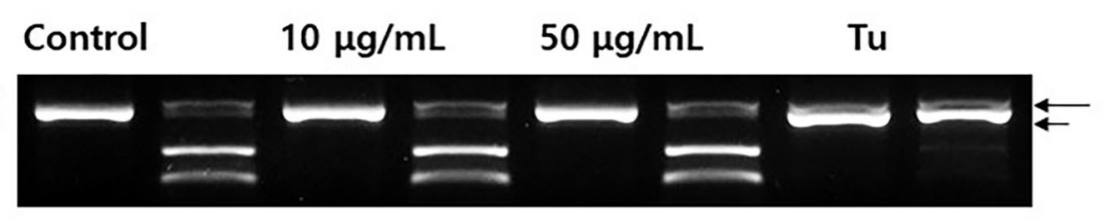

FIGURE 2 | Pectolinarin commands ERSS(Endoplasmic Reticulum-Stress Sensors). (A) The cells were dealt with pectolinarin (10 and $50 \mu \mathrm{g} / \mathrm{ml}$ ) for $24 \mathrm{~h}$. The gene expression of endoplasmic reticulum stress sensors of ATF6, PERK and IRE1 was performed by RT-PCR. (B) Western blotting was performed using anti-elF2- $\alpha$ antibody/elF2- $\alpha$-P antibody, anti-ATF6 monoclonal antibody against cells treated with pectolinarin (10 and $50 \mu \mathrm{g} / \mathrm{ml}$ ) for $24 \mathrm{~h}$, respectively. The resulting bands (fragmented ATF6 and phosphorylated elF2- $\alpha$ ) were estimated by Image $J$ software (version 1.48). (C) RT-PCR was performed against mRNAs of XBP1. The following PCR product was moreover digested by Pstl to disclose a restriction site that was lost following XBP1 splicing under endoplasmic reticulum stress. The following XBP1 cDNA products were disclosed on a 2\% agarose gel. Unspliced XBP1 mRNA made the two lower bands which were indicated by arrows (upper, 290 bp and lower, 183 bp). The spliced XBP1 mRNA pointed out by a bold arrow. ATF6, activating transcription factor; PERK, PKR-like ER kinase (PERK); IRE1, inositol requiring enzyme 1 (IRE1); elF2-alpha-P, phosphorylated form of translation initiation factor elF2 $\alpha$; XBP1, X-box tying protein 1, Tu, tunicamycin, respectively.

expression up to 1.6 times, PERK expression is 1.7 times and IRE1 expression is 1.4 times compared to those of the control, respectively. This result suggests that although pectolinarin does not regulate endoplasmic reticulum chaperone expression directly, it regulates the gene expression of endoplasmic reticulum stress sensors. ATF6 fragmentation by pectolinarin treatment was increased about 2 times compared with its control, and phosphorylation of eIF2 $\alpha$ was increased 2.5 times (Figure 2B). However, there was a little change in the $\mathrm{XBP} 1$ mRNA uncleavaging that means endoplasmic reticulum stress level (Figure 2C). In summary, it has been shown that pectolinarin treatment on PC 12 cells actively regulates endoplasmic reticulum stress sensor activity through both the ATF6 fragmentation and eIF2 $\alpha$ phosphorylation rather than the regulation of ER chaperone gene expression.

\section{Induction of Apoptosis}

If early cellular responses fail to maintain endoplasmic reticulum homeostasis, endoplasmic reticulum stress that activates UPR signal to stimulate the apoptosis as well as this autophagy for cell survival or local cell death. Already, there are already some reports that UPR strongly associated with both apoptosis and autophagy by several regulators, such as for apoptosis (Bax, Bak, Bcl2 and $\mathrm{Bcl}-\mathrm{xl}$ ) and autophagy (LC3a and Beclin) (22). We found that based on the results of Figure 2, nonetheless, pectolinarin induces mild endoplasmic reticulum chaperone expression, the ER stress sensors are actively induced. These findings provide new insights that the mild endoplasmic reticulum stress through PERK-eIF2 $\alpha$ p or/and ATF6 fragmentation indicating pathway has a main role in saving cellular damage from pectolinarin. We therefore tested the role of instantaneous endoplasmic reticulum stress in both apoptosis and autophagy induction of bystander cells treated with pectolinarin. Figure $\mathbf{3 A}$ showed that the pectolinarin induces only the expression of pro-apoptosis (Bax and Bak), no meaningful expression of anti-apoptosis ( $\mathrm{Bcl} 2$ and $\mathrm{Bcl}-$ $\mathrm{xl}$ ) and autophagy (LC3a and Beclin) induction. The result may provide an evidence indicating that pectolinarin induces apoptosis through endoplasmic reticulum stress signaling but not autophagy.

Apoptosis shows two typical cell changes, it morphologically makes apoptotic bodies by cell shrinkage and chromosomal DNA fragmentation. It is being used as a useful marker for identification of apoptotic cells detection of both apoptotic bodies by microscope and apoptotic DNA fragmentation via the DNA laddering assay (23). In this study, to confirm that pectolinarin induces apoptosis, we investigated PC12 cells treated by pectolinarin that shows apoptotic bodies and DNA fragmentation or not. As a result, inter-nucleosomal DNA fragmentation increased in cells treated with pectolinarin dose-dependently (Figure 3B). Moreover, apoptotic bodies were observed following Hoechst 33342 staining (Figure 3C). The 
A

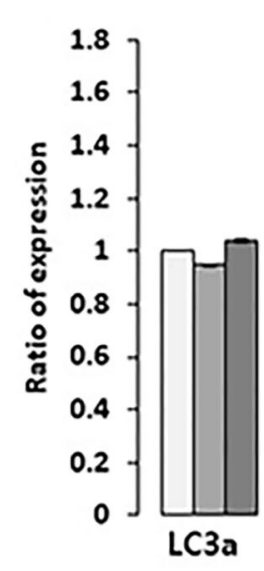

$\square$ Control

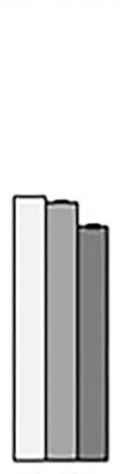

Beclin

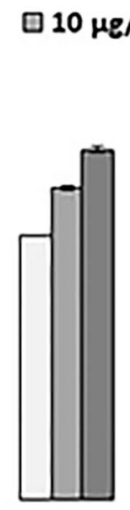

Bax

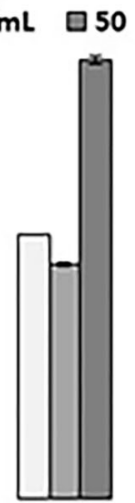

Bak
B

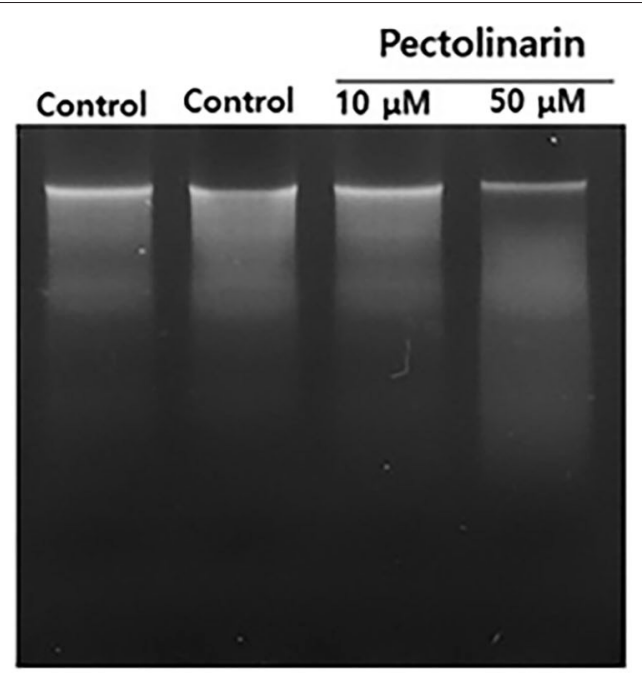

C

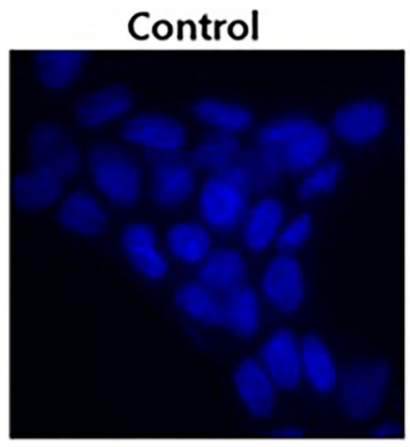

$10 \mu \mathrm{g} / \mathrm{mL}$

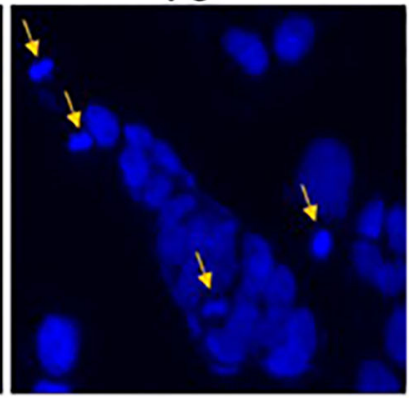

$50 \mu \mathrm{g} / \mathrm{mL}$

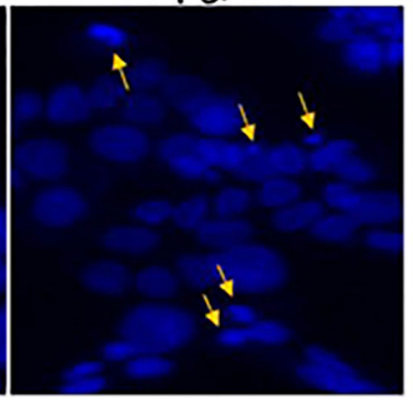

Tu

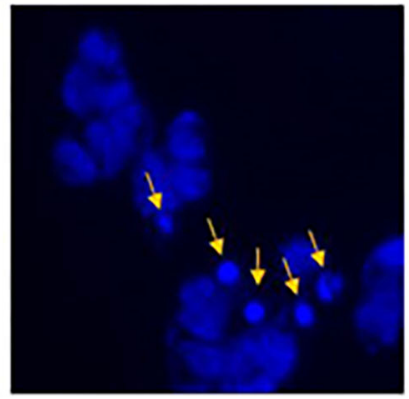

FIGURE 3 | Pectolinarin causes apoptosis in the PC12 cells. (A) The cells were treated with pectolinarin (10 and $50 \mu \mathrm{g} / \mathrm{ml})$ for $24 \mathrm{~h}$. RT-PCR was performed against various mRNAs; LC3a and Beclin-1 LC3a, microtubule-associated protein light chain 3; Beclin, coiled-coil moesin-like BCL2 interacting protein; Bax, Bcl-2-associated X; Bad, Bcl-2-associated death promoter; Bcl-2, B-cell lymphoma 2; Bcl-Xl, B-cell lymphoma/leukemia-x long, respectively. (B) To make sure DNA fragmentation, the cells were dealt with pectolinarin (10 and $50 \mu \mathrm{g} / \mathrm{ml}$ ) for $24 \mathrm{~h}$, respectively. The DNA was lysed on a $1.5 \%$ agarose gel and pictured with Ethidium bromide, an intercalating agent. (C) The cells were dealt with the same conditions of the above (B) and mixed with Hoechst 33342 solution to perceive the formation of apoptotic bodies indicated by arrows. Mixed nuclei were detected from a fluorescent microscope employing a blue filter.

above results clearly revealed that pectolinarin participates in the induction of PC12 cells apoptosis.

In conclusion, pectolinarin dealings obviously caused apoptosis through the expression of ERSS(Endoplasmic Reticulum-Stress Sensors) in the PC12 cells. However, at this time, it is difficult to adequately explain the signaling through endoplasmic reticulum stress triggering several regulators connected with the apoptosis pathway for the extended endoplasmic reticulum stress. It is thought that better understanding of the biological mechanisms focusing pectolinarin-caused apoptosis may be helpful and useful in the diagnosis and treatment of apoptosis-related diseases based on new natural medicinal products.

\section{DATA AVAILABILITY STATEMENT}

The datasets presented in this study can be found in online repositories. The names of the repository/repositories and accession number(s) can be found in the article/supplementary material.

\section{AUTHOR CONTRIBUTIONS}

J-HS gave the conceptual idea. KK developed the methodology work. O-YK helped in implementation work. E-RL helped in result analysis work. S-WK helped in documentation work. $\mathrm{K}-\mathrm{HK}$ helped in final editing and drafting of manuscript. All authors contributed to the article and approved the submitted version.

\section{FUNDING}

This work was supported by the National Research Foundation of Korea (NRF) grant funded by the Korea government(Ministry of Education) (No. NRF-2017R1D1A1B03035544). 


\section{REFERENCES}

1. Lee YN. Flora of Korea. Seoul: Kyohaksa. (2002) p. 843.

2. Kim JG. Illustrated Natural Drugs Encyclopedia. Seoul: Namsandang. (1984) p. 37.

3. Hertog MGL, Kromhout D, Aravanis C, Blackburn H, Buzina R, Ridanza $\mathrm{F}$, et al. Flavonoid intake and long-term risk of coronary heart disease and cancer in the seven countries study. Arch Int Med. (1995) 155:3816. doi: 10.1001/archinte.155.4.381

4. Heo J. Dongui Bogam. Seoul: Bubin Publishers Co. (1999). p. 1942.

5. Jung JH, Kim Y, Lee CO, Kang SS, Park JH, Im KS. Cytotoxic constituents of Saussurea lappa. Arch Pharm Res. (1998) 21:153-6. doi: 10.1007/BF02974020

6. Jeong DM, Jung HA, Choi JS. Comparative antioxidant activity and HPLC profiles of some selected Korean thistles. Arch Pharm Res. (2008) 31:2833 doi: 10.1007/s12272-008-1116-7

7. Yoo YM, Nam JH, Kim MY, Choi J, Park HJ. Pectolinarin and pectolinarigenin of cirsium setidens prevent the hepatic injury in rats caused by Dgalactosamine via an antioxidant mechanism. Biol Pharm Bull. (2008) 31:7604 doi: $10.1248 / \mathrm{bpb} .31 .760$

8. Cho S, Lee J, Lee YK, Chung MJ, Kwon KH, Lee S. Determination of pectolinarin in Cirsium spp. using HPLC/UV analysis. J Appl Biol Chem. (2016) 59:107-12. doi: 10.3839/jabc.2016.020

9. Jung JE, Sin SM, Kim HM, Lee S, Choi K, Park KW, et al. Screening of radical scavenging activity and gastric cancer prevention activity from Korean folk plants. Cancer Prev Res. (2011) 16:65-73 Available online at: http://www. jcpjournal.org/journal/view.html?volume $=16 \&$ number $=1 \&$ spage $=65$

10. Thao NT, Cuong TD, Hung TM, Lee JH, Na M, Son JK, et al. Simultaneous determination of bioactive flavonoids in some selected Korean thistles by high-performance liquid chromatography. Arch Pharm Res. (2011) 34:45561. doi: 10.1007/s12272-011-0314-x

11. Lee S, Lee DH, Kim JC, Um BH, Sung SH, Jeong LS, et al. Pectolinarigenin, an aglycone of pectolinarin, has more potent inhibitory activities on melanogenesis than pectolinarin. Biochem Biophys Res Commun. (2017) 493:765-72. doi: 10.1016/j.bbrc.2017.08.106

12. Hwang J, Qi L. Quality control in the endoplasmic reticulum: crosstalk between ERAD and UPR pathways. Trends Biochem Sci. (2018) 43:593605. doi: 10.1016/j.tibs.2018.06.005

13. Back SH, Kaufman RJ. Endoplasmic reticulum stress and type 2 diabetes. Annu Rev Biochem. (2012) 81:76793. doi: 10.1146/annurev-biochem-072909-095555

14. Schröder M, Kaufman RJ. ER stress and the unfolded protein response. Mutat Res. (2005) 569:29-63. doi: 10.1016/j.mrfmmm.2004.06.056
15. Schröder M, Kaufman RJ. The mammalian unfolded protein response. Annu Rev Biochem. (2005) 74:73989. doi: 10.1146/annurev.biochem.73.011303.074134

16. Chouhan V, Kumar SS, Khamparia A, Gupta D, Tiwari P, Moreira C, et al. A novel transfer learning based approach for pneumonia detection in chest X-ray images. Appl Sci. (2020) 10:559. doi: 10.3390/app100 20559

17. Khamparia A, Saini G, Gupta D, Khanna A, Tiwari S, Albuquerque VHC. Seasonal crops disease prediction and classification using deep convolutional encoder network. Circuits Syst Signal Process. (2020) 39:81836. doi: 10.1007/s00034-019-01041-0

18. Lee YJ, Lee JH, Kim YH, Kim JH, Yu SY, Kim DB, et al. Assessment of the pectolinarin content and the radical scavenging-linked antiobesity activity of Cirsium setidens Nakai extracts. Food Sci Biotechnol. (2015) 24:223543. doi: 10.1007/s10068-015-0298-2

19. Roth JA, Horbinski C, Higgins D, Lein P, Garrick MD. Mechanisms of manganese-induced rat pheochromocytoma (PC12) cell death and cell differentiation. Neurotoxicology. (2002) 23:147-57. doi: 10.1016/S0161-813X(01)00077-8

20. Khamparia A, Singh A, Anand D, Gupta D Khanna A, Kumar NA, et al. A novel deep learning-based multi-model ensemble method for the prediction of neuromuscular disorders. Neural Comput Appl. (2020) 32:11083-95. doi: 10.1007/s00521-018-3896-0

21. Parmar VM, Schröder M. Sensing endoplasmic reticulum stress. Adv Exp Med Biol. (2012) 738:153-68. doi: 10.1007/978-1-4614-1680-7_10

22. Song S, Tan J, Miao Y, Li M, Zhang Q. Crosstalk of autophagy and apoptosis: involvement of the dual role of autophagy under ER stress. J Cell Physiol. (2017) 232:2977-84. doi: 10.1002/jcp.25785

23. Elmore S. Apoptosis: a review of programmed cell death. Toxicol Pathol. (2007) 35:495-516. doi: 10.1080/01926230701320337

Conflict of Interest: The authors declare that the research was conducted in the absence of any commercial or financial relationships that could be construed as a potential conflict of interest.

Copyright (C) 2020 Song, Kwon, Kwon, Lee, Kim and Kang. This is an open-access article distributed under the terms of the Creative Commons Attribution License (CC $B Y)$. The use, distribution or reproduction in other forums is permitted, provided the original author(s) and the copyright owner(s) are credited and that the original publication in this journal is cited, in accordance with accepted academic practice. No use, distribution or reproduction is permitted which does not comply with these terms. 